\title{
HUBUNGAN AKTIVITAS FISIK MINGGUAN, TINGKAT KONSUMSI KARBOHIDRAT DAN SERAT DENGAN KADAR GULA DARAH LANJUT USIA AWAL DAN AKHIR DI POSBINDU SEHATI
}

\author{
The Relation between Weekly Physical Activity, the Level Consumption of \\ Carbohydrates and Fibers on Blood Sugar Concetration of The Beginning and \\ End The Elderly at Posbindu Sehati
}

\author{
Amelya Irnawati ${ }^{1}$, Endo Dardjito ${ }^{2}$, dan Saryono $^{3}$ \\ ${ }^{1)}$ Program Studi Ilmu Gizi FIKES, ${ }^{2)}$ Jurusan Kesmas FIKES, ${ }^{3)}$ Jurusan Keperawatan FIKES \\ Universitas Jenderal Soedirman \\ J1. Dr. Soeparno, Karangwangkal Purwokerto 53123 \\ Alamat Koerspondensi: amelyairnawati26@gmail.com
}

\begin{abstract}
The incidence of Diabetes Melitus has increased. Someone with age $>45$ years has exposed the risk of Diabetes Melitus. Increasing of Diabetes Melitus can increase the risk of other diseases and death. Treatment on people affected by the disease of Diabetes Melitus can be done through the intake of food and physical activity. Find out about relation between weekly physical activity, the level consumption of carbohydrates and fibers on blood sugar concetration of the beginning and end the elderly at Posbindu Sehati. Total of the respondents are 46 and all of them are female by the average age 54.72. 41 respondents are graduated from primary school and Junior High school. The average of physical activity respondents is 4364.98. 23 people included in the category of less of the level consumption of carbohydrates. While the level consumption of respondents entirely fiber was much less. The result showed that the physical activity, the level consumption of carbohydrates and fibers had no relationship with blood sugar fasting month in elderly the beginning and the end with $\mathrm{p}$ each $0.661 ; 0.327$; and 0.530 . The results show that the variable physical activity, the level consumption of carbohydrates and fibers has no relationship with fasting blood sugar levels at the beginning and end of the elderly with value $\mathrm{p}$ each 0.661 ; 0.327; and 0.530. Physical activity, the level consumption of carbohydrates and fibers not related with fasting blood sugar levels.
\end{abstract}

Keywords: Physical activity, carbohydrates, fibers, fasting blood sugar levels.

\begin{abstract}
ABSTRAK
Latar Belakang: Kejadian Diabetes Melitus telah meningkat. Seseorang dengan usia> 45 tahun telah terkena risiko Diabetes Melitus. Meningkatnya Diabetes Melitus dapat meningkatkan risiko penyakit dan kematian lainnya. Pengobatan pada orang yang terkena penyakit Diabetes Melitus bisa dilakukan melalui asupan makanan dan aktivitas fisik. Tujuan Penelitian: Cari tahu tentang hubungan antara aktivitas fisik mingguan, tingkat konsumsi karbohidrat dan serat pada concetration gula darah awal dan akhir lansia di Posbindu Sehati. Metodologi: Jumlah responden adalah 46 dan semuanya perempuan dengan usia rata-rata 54,72. 41 responden lulus dari sekolah dasar dan sekolah menengah pertama. Rata-rata aktivitas fisik responden adalah 4364,98. 23 orang termasuk dalam kategori kurang dari tingkat konsumsi karbohidrat. Sedangkan tingkat konsumsi responden seluruhnya serat jauh lebih sedikit. Hasil penelitian menunjukkan bahwa aktivitas fisik, tingkat konsumsi karbohidrat dan serat tidak memiliki hubungan dengan bulan puasa gula pada lansia awal dan akhir dengan $\mathrm{p}$ masing-masing 0,661; 0,327; dan 0,530 Hasil Penelitian: Hasil penelitian menunjukkan bahwa variabel aktivitas fisik, tingkat konsumsi karbohidrat dan serat tidak memiliki hubungan dengan tingkat gula darah puasa pada awal dan akhir lansia dengan nilai $\mathrm{p}$ masing-masing sebesar 0,$661 ; 0,327$; dan 0,530 . Kesimpulan: Aktivitas fisik, tingkat konsumsi karbohidrat dan serat tidak berhubungan dengan kadar gula darah puasa.
\end{abstract}

Kata kunci: Aktivitas fisik, karbohidrat, serat, kadar gula darah puasa. 


\section{PENDAHULUAN}

Diabetes Melitus (DM) merupakan sekelompok kondisi yang ditandai dengan kenaikan kadar glukosa darah (hiperglikemia) akibat adanya defisiensi insulin yang absolut ataupun relatif (Mann dan Truswell, 2014). Seseorang dikategorikan diabetes mellitus apabila memiliki kadar glukosa darah sewaktu $\geq 200$ mg/dl (Rudijanto dkk, 2015). Kejadian diabetes mellitus setiap tahunnya mengalami peningkatan oleh karena adanya perubahan gaya hidup masyarakat. Data Profil Kesehatan Provinsi Jawa Tengah menunjukkan bahwa prevalensi kasus baru diabetes mellitus pada tahun 2013, 2014 dan 2015 secara berturut-turut mengalami kenaikan yaitu $14,24 \%, 16,53 \%$, dan 18,33\% (Dinkes Jawa Tengah, 2015).

Penduduk usia kerja adalah penduduk yang memiliki usia 15 - 64 tahun (Badan Pusat Statistik Indonesia, 2013). Seseorang dapat dikatakan memiliki risiko terkena diabetes mellitus salah satunya adalah memiliki usia di atas 45 tahun (Rudijanto dkk, 2015). Berdasarkan data Kementerian Kesehatan RI (2013), angka kejadian diabetes mellitus pada tahun 2013 di Provinsi Jawa Tengah meningkat berturut-turut mulai dari usia 15 tahun sampai dengan 64 tahun, yaitu $0,3 \%$ (usia 15 - 24 tahun), $0,5 \%$ (usia 25 - 34 tahun), 1,6\% (usia 35 - 44 tahun), 3,5\% (usia $45-54$ tahun), dan 4,6\% (usia 55 - 64 tahun). Data tersebut menunjukkan peningkatan paling besar pada usia 45 - 54 tahun.

Penatalaksanaan yang efektif pada penderita diabetes mellitus tidak hanya dengan menggunakan terapi insulin, melainkan juga memerlukan beberapa hal yang harus di kontrol, yaitu rencana diet, latihan fisik dan aktivitas fisik, agen-agen hipoglikemik oral, pengawasan glukosa di rumah, serta pengetahuan tentang diabetes dan perawatan dini Beberapa rencana diet yang dianjurkan adalah pembatasan konsumsi karbohidrat dan makanan yang kaya serat. Karbohidrat yang dikonsumsi harus diatur sesuai dengan kebutuhan masing-masing orang dan tidak boleh berlebihan (Price dan Wilson, 2005).
Makanan kaya serat juga dianjurkan pada penderita diabetes karena dapat memperbaiki kontrol glikemik (Mann dan Truswell, 2014). Selain itu, latihan fisik dan aktivitas fisik pada penderita diabetes juga merupakan faktor yang penting karena dapat mempermudah transport glukosa ke dalam sel dan dapat meningkatkan kepekaan terhadap insulin sehingga kadar gula darah dapat terkendali (Price dan Wilson, 2005).

Prevalensi Penyakit Tidak Menular (PTM) meningkat dari 49,9\% pada tahun 2001 menjadi 59,5\% di tahun 2007 (Depkes RI, 2008). Semakin meningkatnya prevalensi penyakit tidak menular maka diperlukan adanya program untuk mengendalikannya, salah satunya yaitu Posbindu PTM (Pos Pembinaan Terpadu Penyakit Tidak Menular). Salah satu Posbindu di Kabupaten Banyumas yang aktif dan memiliki kejadian diabetes mellitus tidak tergantung insulin tertinggi ke 4 pada tahun 2016 (109 kejadian) adalah Posbindu Sehati, Desa Panusupan, Kecamatan Cilongok (Dinas Kesehatan Banyumas, 2016). Berdasarkan latar belakang tersebut, maka peneliti tertarik untuk meneliti hubungan aktivitas fisik mingguan, tingkat konsumsi karbohidrat dan serat dengan kadar gula darah puasa pada lansia awal dan lansia akhir di Posbindu Sehati, Desa Panusupan, Kecamatan Cilongok. Tujuan pada penelitian ini adalah mendeskripsikan karakteristik responden yang terdiri dari usia, jenis kelamin, pendidikan, aktivitas fisik mingguan, tingkat konsumsi karbohidrat dan serat, serta kadar gula darah puasa responden, menganalisis hubungan aktivitas fisik mingguan dengan kadar gula darah puasa, menganalisis hubungan tingkat konsumsi karbohidrat dengan kadar gula darah puasa, dan menganalisis hubungan tingkat konsumsi serat dengan kadar gula darah puasa pada lansia awal dan akhir di Posbindu Sehati, Desa Panusupan, Kecamatan Cilongok.

\section{METODE PENELITIAN}

Penelitian ini menggunakan desain penelitian cross-sectional yang dilaksanakan di Posbindu Kabupaten Banyumas mulai 
dari bulan April sampai dengan Juni 2017. Populasi dalam penelitian ini adalah seluruh pengunjung yang terdapat di Posbindu Sehati, yaitu sejumlah 75 orang dan untuk pengambilan sampel menggunakan total sampling dengan kriteria inklusi: (1) berusia 46 - 64 tahun, (2) mampu berkomunikasi dengan baik. Variabel independen dalam penelitian ini adalah usia, jenis kelamin, pendidikan, aktivitas fisik mingguan, tingkat konsumsi karbohidrat, dan tingkat konsumsi serat, dan variabel dependennya adalah kadar gula darah puasa. Instrumen dalam penelitian ini yaitu kuesioner yang terdiri dari form data diri responden, form recall 24 jam, International Physical Activity Questionnaire (IPAQ) serta Accu Chek untuk alat ukur gula darah puasa. Alur penelitian dimulai dari penyusunan proposal, pengambilan data di posbindu, konsultasi dengan pembimbing, analisis data dan penyusunan laporan. Data dianalisis menggunakan Pearson Product Moment karena data dalam bentuk rasio.

\section{HASIL DAN PEMBAHASAN}

\section{A. Hasil}

\section{Analisis Univariat}

Distribusi responden berdasarkan usia dan jenis kelamin dapat dilihat pada Tabel 1.

Tabel 1. Distribusi Responden Berdasarkan Usia dan Jenis Kelamin

\begin{tabular}{|c|c|c|c|}
\hline \multirow{2}{*}{$\begin{array}{c}\text { Jenis } \\
\text { Kelamin }\end{array}$} & \multirow[b]{2}{*}{$\mathrm{n}$} & \multirow[b]{2}{*}{$\%$} & Usia \\
\hline & & & Mean SD \\
\hline Perempuan & 46 & 100 & 54,72 \\
\hline Laki-laki & 0 & 0 & \\
\hline
\end{tabular}

Berdasarkan Tabel 1. Diperoleh bahwa responden seluruhnya berjenis kelamin perempuan $(100 \%)$ dan ratarata usianya 54,72 .

Tabel 2. Distribusi Responden Berdasarkan Pendidikan

\begin{tabular}{ccc}
\hline Pendidikan & $\mathrm{n}$ & $\%$ \\
\hline Tidak Sekolah & 3 & 6,5 \\
Pendidikan Dasar & 41 & 89,1 \\
Pendidikan Menengah & 2 & 4,3 \\
Pendidikan Tinggi & 0 & 0 \\
\hline
\end{tabular}

Berdasarkan Tabel 2. diperoleh bahwa sebagian besar responden berpendidikan dasar sebanyak 41 responden $(89,1 \%)$.

Nilai rata-rata aktivitas fisik mingguan responden sebesar 4364,98 dalam METmenit/minggu dengan nilai standar deviasi (SD) sebesar 3028,97. Kategori aktivitas fisik responden dapat dilihat pada Tabel 3.

Tabel 3. Kategori Aktivitas Fisik Responden

\begin{tabular}{ccc}
\hline Kategori & $\mathrm{n}$ & $\%$ \\
\hline Rendah & 2 & 4,3 \\
Sedang & 11 & 23,9 \\
Berat & 33 & 71,7 \\
\hline
\end{tabular}

Berdasarkan Tabel 3. diperoleh bahwa sebagian besar responden memiliki aktivitas fisik berat yaitu sebanyak 33 orang $(71,7 \%)$.

Nilai rata-rata, minimum, dan maximum konsumsi karbohidrat responden berturut-turut sebesar 194,92 gram; 94,1 gram; dan 336,55 gram. Kategori tingkat konsumsi karbohidrat responden dapat dilihat pada Tabel 4.

Tabel 4. Kategori Tingkat Konsumsi Karbohidrat Responden

\begin{tabular}{ccc}
\hline Kategori & $\mathrm{n}$ & $\%$ \\
\hline Sangat Kurang & 16 & 34,8 \\
Kurang & 23 & 50 \\
Normal & 6 & 13 \\
Lebih dari AKG & 1 & 2,2
\end{tabular}

Berdasarkan Tabel 4. diperoleh bahwa tingkat konsumsi karbohidrat responden sebagian besar kurang (50\%).

Nilai rata-rata, minimum dan maximum konsumsi serat responden berturut-turut sebesar 6,33 gram; 2,75 gram; dan 12,65 gram. Kategori tingkat konsumsi serat responden dapat dilihat pada Tabel 5. 
Tabel 5. Kategori Tingkat Konsumsi

\begin{tabular}{ccc}
\multicolumn{3}{c}{ Serat } \\
\hline Kategori & $\mathrm{n}$ & $\%$ \\
\hline Sangat Kurang & 46 & 100 \\
Kurang & 0 & 0 \\
Normal & 0 & 0 \\
Lebih dari AKG & 0 & 0
\end{tabular}

Berdasarkan Tabel 5. diperoleh bahwa seluruh responden memiliki tingkat konsumsi serat sangat kurang (100\%).

Nilai rata-rata, minimum dan maximum kadar gula darah puasa responden berturut-turut sebesar 125,21 $\mathrm{mg} / \mathrm{dL} ; 86 \mathrm{mg} / \mathrm{dL} ;$ dan $313 \mathrm{mg} / \mathrm{dL}$. Kategori kadar gula darah puasa responden dapat dilihat pada Tabel 6 .

Tabel 6. Distribusi Kadar Gula Darah Puasa Responden

\begin{tabular}{ccc}
\hline Kategori & $\mathrm{n}$ & $\%$ \\
\hline Normal & 18 & 39,1 \\
Lebih dari normal & 28 & 60,9
\end{tabular}

Berdasarkan Tabel 6. diperoleh bahwa kadar gula darah puasa responden sebagian besar lebih dari normal $(60,9 \%)$.

\section{Analisis Bivariat}

Berdasarkan Tabel 7. diperoleh bahwa tidak terdapat hubungan aktivitas fisik mingguan dengan kadar gula darah puasa responden dengan nilai $\mathrm{p}=0,661$.

Tabel 7. Hubungan Aktivitas fisik Mingguan dengan Kadar Gula Darah Puasa Responden

\begin{tabular}{ccc}
\hline Variabel & $\mathrm{r}$ & $\mathrm{p}$ \\
\hline $\begin{array}{c}\text { Aktivitas fisik } \\
\text { mingguan }\end{array}$ & & \\
$\begin{array}{c}\text { Kadar gula darah } \\
\text { puasa }\end{array}$ & 0,067 & 0,661
\end{tabular}

Berdasarkan Tabel 8. diperoleh bahwa tidak terdapat hubungan antara tingkat konsumsi karbohidrat ataupun tingkat konsumsi serat dengan kadar gula darah puasa responden dengan nilai $\mathrm{p}$ masing-masing yaitu 0,327 dan 0,530 .
Tabel 9. Hubungan Tingkat Konsumsi dengan Kadar Gula Darah Puasa Responden

\begin{tabular}{ccc}
\hline Variabel & $\mathrm{R}$ & $\mathrm{p}$ \\
\hline $\begin{array}{c}\text { Tingkat Konsumsi } \\
\text { Karbohidrat }\end{array}$ & $-0,148$ & 0,327 \\
$\begin{array}{c}\text { Tingkat Konsumsi } \\
\text { Serat }\end{array}$ & $-0,095$ & 0,530 \\
\hline
\end{tabular}

\section{B. Pembahasan}

1. Hubungan Aktivitas Fisik Mingguan dengan Kadar Gula Darah Puasa

Analisis bivariat menggunakan Rank Spearman menunjukkan bahwa tidak ada hubungan antara aktivitas fisik mingguan dengan kadar gula darah responden (nilai $p>0,05)$. Hal yang menyebabkan tidak adanya hubungan antara aktivitas fisik mingguan responden dengan kadar gula darah puasa responden adalah aktivitas fisik yang diukur merupakan aktivitas fisik mingguan dan bukan aktivitas fisik sesaat sebelum pemeriksaan kadar gula darah puasa sehingga tidak mempengaruhi kadar gula darah puasa responden meskipun responden memiliki aktivitas fisik yang berat. Kadar gula darah responden akan terlihat perubahannya apabila dilakukan pengecekan sesaat setelah melakukan aktivitas fisik. Pada dasarnya, aktivitas fisik dapat mempengaruhi kadar glukosa dalam darah. Ketika aktivitas fisik tubuh tinggi, maka penggunaan glukosa oleh otot akan ikut meningkat sehingga dapat menurunkan kadar glukosa dalam darah (Kronenberg, 2008). Hasil ini sejalan dengan penelitian yang dilakukan oleh Khairunnisa (2016), diperoleh bahwa tidak terdapat hubungan antara level aktivitas fisik dengan kadar glukosa darah subjek, dimana data aktivitas fisik tersebut diperoleh dari activity recall 2x24 jam di hari kerja dan libur.

\section{Hubungan Tingkat Konsumsi Karbohidrat dengan Kadar Gula Darah Puasa}

Berdasarkan hasil uji statistik menggunakan Pearson Product Moment, diperoleh bahwa tidak terdapat hubungan antara tingkat konsumsi karbohidrat dengan kadar gula darah puasa responden dengan nilai $\mathrm{p}=0,327$. Hasil ini sejalan dengan 
penelitian yang dilakukan oleh Rahmawati (2010), yang menunjukkan bahwa tidak terdapat hubungan antara konsumsi karbohidrat dengan kadar glukosa darah puasa $(\mathrm{p}=0,528)$ dan 2JPP $(\mathrm{p}=0,616)$ pada penderita diabetes mellitus tipe 2 rawat jalan di RSD Kalisat Kabupaten Jember.

Hal yang menyebabkan tidak berhubungannya tingkat konsumsi karbohidrat dengan kadar gula darah puasa responden karena adanya faktor lain yang mempengaruhi, salah satunya adalah usia. Adanya pertambahan usia menyebabkan terjadinya penurunan fisiologis pada seseorang, khususnya setelah usia 40 tahun. Penurunan fisiologis yang terjadi akan beresiko pada penurunan fungsi endokrin pankreas untuk memproduksi insulin (Arisman, 2011). Penurunan produksi insulin dan sensitifitas jaringan mempengaruhi metabolisme glukosa seseorang yang akhirnya menyebabkan terjadinya hiperglikemia (kenaikan kadar gula darah) pada lanjut usia (MCCann, 2002). Penelitian Ko et al., (2006) diperoleh bahwa ada hubungan antara kadar gula darah plasma (gula darah puasa, 2 jam postprandial, dan pemeriksaan pada waktu yang berbeda-beda / acak dengan usia.

\section{Hubungan Tingkat Konsumsi Serat dengan Kadar Gula Darah Puasa}

Berdasarkan hasil uji statistik menggunakan Pearson Product Moment, diperoleh bahwa tidak terdapat hubungan antara tingkat konsumsi serat dengan kadar gula darah puasa responden dengan nilai $p=0,530 \quad(p>0,05)$. Hasil ini tidak sejalan dengan penelitian yang dilakukan oleh Muliani (2013) yang menyatakan bahwa terdapat hubungan antara asupan serat dengan kadar gula darah puasa pada penderita dm-tipe 2 di poliklinik penyakit dalam RSUD dr. H. Abdul Moeloek Provinsi Lampung.

Tingginya kadar gula darah seseorang dipengaruhi oleh multifaktor, antara lain genetik, obesitas, pola makan, aktivitas fisik, dan kerusakan organ (WHO, 2006). Pada penelitian ini faktor yang menyebabkan tidak adanya hubungan antara tingkat konsumsi serat dengan kadar gula darah puasa yaitu Indeks Massa Tubuh (IMT). Adanya peningkatan jaringan lemak dalam tubuh pada seseorang dengan IMT> $25 \mathrm{~kg} / \mathrm{m} 2$ (gemuk) menginduksi terjadinya resistensi insulin. Resistensi insulin adalah suatu keadaan terjadinya gangguan respons metabolik terhadap sensitivitas insulin (Reaven, 2006). Manifestasi dari resistensi insulin ini ditandai dengan peningkatan pada kadar gula darah puasa dan kadar gula darah sewaktu (Merentek, 2006). Seperti pada penelitian yang dilakukan oleh Vittal et al, (2010) pada 400 orang dengan usia $21-60$ tahun yang menunjukkan adanya hubungan $(\mathrm{r}=+0,26)$ antara IMT dengan kadar gula darah puasa. Nilai korelasi yang positif menunjukkan bahwa semakin tinggi IMT seseorang maka semakin tinggi pula kadar gula darah puasa. Peningkatan IMT ini terjadi seiring dengan peningkatan usia seseorang. Pada penelitian ini, diketahui bahwa sebagian besar responden memiliki IMT $>25 \mathrm{~kg} / \mathrm{m} 2$ (status gizi gemuk) yaitu sebanyak 25 responden $(54,3 \%)$. Hal inilah yang dapat mempengaruhi kadar gula darah puasa responden.

\section{KESIMPULAN}

Berdasarkan penelitian yang telah dilakukan, diperoleh kesimpulan yaitu Aktivitas fisik responden sangat bervariasi dengan nilai rata-rata sebesar 4364,98 dalam METmenit/minggu, Sebagian besar responden (50\%) mempunyai tingkat konsumsi karbohidrat yang tergolong kurang dengan nilai rata-rata sebesar $78,19 \%$, Seluruh responden $(100 \%)$ mempunyai tingkat konsumsi serat yang tergolong sangat kurang dengan nilai rata-rata sebesar $26,1 \%$. Tidak ada hubungan antara aktivitas fisik mingguan dengan kadar gula darah puasa pada lanjut usia awal dan akhir di Posbindu Sehati. Tidak ada hubungan antara tingkat konsumsi karbohidrat dengan kadar gula darah puasa pada lanjut usia awal dan akhir di Posbindu Sehati. Tidak ada hubungan antara tingkat konsumsi serat dengan kadar gula darah puasa pada lanjut usia awal dan akhir di Posbindu Sehati. Perlu adanya 
penelitian yang lebih mendalam mengenai aktivitas fisik seseorang agar terlihat hubungannya dengan variabel lain.

\section{DAFTAR PUSTAKA}

Arisman, 2011, Buku Ajar Ilmu Gizi Obesitas, Diabetes Mellitus dan Dislipidemia, EGC, Jakarta.

Badan Pusat Statistik Indonesia, 2013, Proyeksi Penduduk Indonesia,Indonesia Population Projection 2010 - 2035, Badan Pusat Statistik, Jakarta-Indonesia, 26.

Depkes RI, 2008, Riset Kesehatan Dasar Tahun 2007, Depkes RI, Jakarta.

Dinkes Jawa Tengah, 2015, Profil Kesehatan Provinsi Jawa Tengah 2015, Dinkes Jawa Tengah, Semarang.

Kementerian Kesehatan RI, 2013, Riset Kesehatan Dasar 2013 Provinsi Jawa Tengah, Kemenkes RI.

Khairunnisa, N., 2016, Hubungan Kebiasaan Merokok, Aktivitas Fisik, Konsumsi Gula dan Status Gizi dengan Kadar Malondialdehide (MDA) dan Glukosa Darah pada Orang Dewasa, Skripsi, Institut Pertanian Bogor, Bogor.

Ko, G. TC., Wai, H. PS., Tang, J. SF., Effects of Age on Plasma Glucose Levels in Non-diabetic Hongkong Chinese, Croat Med J, 47: 712.

Kronenberg, H. M., Melmed, S., Polonsky, K. S., dan Larsen, P. R., 2008, Williams Textbook of Endocrinology. 11th Ed. Saunders, Philadelphia.

Mann, J. dan Truswell, A. S., 2014, Buku Ajar Ilmu Gizi, EGC, Jakarta, 351, 354, 359-362.

MCCann, J. A., dan German, M. S., 2002, Better Elder Care: A Nurse's Guide to Caring for Older Adult, Pennsylvannia, Springhouse.

Merentek, E., 2006, Resistensi Insulin pada Diabetes Mellitus tipe 2, Cermin Dunia Kedokteran.

Muliani, Usdeka, 2013, Asupan Zat-zat Gnizi dan Kadar Gula Darah Penderita DM-Tipe 2 di Poliklinik Penyakit Dalam di RSUD Dr. H. Abdul Moeloek Provinsi Lampung, Jurnal Kesehatan, 4 (2): 331.
Price, S. A dan Wilson, L. M., 2005, Patofisiologi: Konsep Klinis Prosesproses Penyakit, Penerbit EGC, Jakarta, 1264 - 1270.

Rahmawati, E., 2010, Hubungan antara Konsumsi Karbohidrat dan Serat dengan Kadar Glukosa Darah (Studi pada Penderita Diabetes Mellitus tipe 2 Rawat Jalan di RSD Kalisat Kabupaten Jember), Skripsi, Universitas Jember, Jember.

Reaven, G. M., 2006, The Metabolic Syndrome: is This Diagnosis Necessary? Am J Clin Nutr, 83.

Rudijanto, A., Yuwono, A., Shahab, A., Manaf, A., Pramono, B., Lindarto, D., Purnamasari, D., Sanusi, H., Zufry, H., Novida, H., Suastika, K., Sucipto, K. W., Sasiarini, L., Dwipayana, M. P., Saraswati, M. R., Soetedjo, N. N., Soewondo, P., Soelistijo, S. A., Sugiarto, Langi,Y. A., 2015, Konsensus Pengelolaan Dan Pencegahan Diabetes Melitus Tipe 2 Di Indonesia 2015, PB Perkeni, 15.

Vittal, B. G., Praveen, G., Deepak, P. A., Study Of Body Mass Index In Healthy Individuals And Its Relationship With Fasting Blood Sugar. Journal of Clinical And Diagnostic Research, 4 (6): 3421.

World Health Organization (WHO), 2006, Definition and Diagnosis of Diabetes Mellitus and Intermediate Hyperglycaemia, WHO Press, Geneva $(\mathrm{CH})$. 